\title{
Políticas educativas e auto- avaliação da escola pública portuguesa: apontamentos de uma experiência
}

ALMERINDO JANELA AFONSO*

\section{RESUMO}

A centralidade que a avaliaçâo tem vindo a assumir nas últimas décadas, em múltiplos contextos nacionais, não dá sinais de declínio e, pelo contrário, parece expandir-se para domínios muito diferentes, para além do campo da educação. A avaliação institucional das escolas ou, simplesmente, a avaliação das escolas, inscrevendo-se num ímpeto avaliador que tem sido impulsionado, entre outros, por factores político-ideológicos, educacionais, económicos e culturais, pode ser referenciada, consoante os casos, a modelos e experiências diversos que estáo, eles próprios, em etapas de implementação e consolidação muito distintas. No caso português, a avaliação das escolas começou por ter alguma visibilidade ao longo da década de noventa, nomeadamente com o Observatório da Qualidade da Escola, tendo evoluído discretamente até conseguir algum impacto na década seguinte com o programa de Avaliação Integrada das Escolas. Actualmente, está em curso a concretizaçáo de um outro modelo, designado de Avaliação Externa das Escolas, em que todos os estabelecimentos de ensino estatais foram, ou serão ainda, incluídos neste mesmo ciclo avaliativo (2006-2011). Partindo desta experiência, o artigo faz um enquadramento sucinto e uma reflexão crítica

* Sociólogo, Doutor em Educação, Professor Associado do Departamento de Ciências Sociais da Educaçáo da Universidade do Minho (Portugal), e membro do Centro de Investigaçáo em Educação (CIEd) (ajafonso@ie.uminho.pt). 
sobre a componente de auto-avaliaçáo do modelo actual de avaliaçáo institucional das escolas portuguesas.

Palavras-chave: Políticas educacionais, Avaliaçáo institucional, Auto-avaliação, Portugal, Escolas.

\section{RESUMEN}

La importancia que la evaluación ha llegado a asumir en las últimas décadas, en múltiples contextos nacionales, no muestra seńales de declive $y$, por el contrario, parece expandirse en dominios muy diferentes, más allá del campo de la educación. La evaluación institucional de las escuelas o, simplemente, la evaluación de las escuelas, que se inscribe en el ímpetu evaluador que ha sido impulsado, entre otros, por factores político-ideológicos, educativos, económicos y culturales, puede referirse, según los casos, a modelos y experiencias diversos que están, ellos mismos, en etapas muy distintas de implementación y consolidación. En el caso portugués, la evaluación de las escuelas comenzó a tener alguna visibilidad a lo largo de la década de los noventa, principalmente con el Observatorio de la Calidad de la Escuela, que ha evolucionado discretamente hasta conseguir algún impacto en la década siguiente con el programa de Evaluación Integrada de las Escuelas. Actualmente, está en curso la concretización de otro modelo, designado como Evaluación Externa de las Escuelas, en el que todos los establecimientos de enseñanza estatales estuvieron, o están todavía, incluidos en el mismo ciclo de evaluación (2006-2011). Teniendo en cuenta esta experiencia, el artículo hace un encuadramiento sucinto y una reflexión crítica esencialmente sobre el componente de autoevaluación de este último modelo de evaluación institucional de las escuelas portuguesas.

Palabras clave: Política educativas, Evaluación institucional, Auto-evaluación, Portugal, escuelas.

\section{ABSTRACT}

The central role that evaluation has taken on over the last few decades, in a variety of national contexts, shows no signs of abating and, on the contrary, seems to be expanding to very different domains, beyond the field of education. The institutional evaluation of schools, or simply the evaluation of schools, as part of the impetus for evaluation that has been driven by, among others, political-ideological, educational, economic and cultural factors, can be tied to, depending on the cases, different models and experiences which are themselves at very different stages of implementation and consolidation. In the Portuguese case, the evaluation of schools began to gain some visibility throughout the 1990 s, for example with the School Quality Observatory, and evolved cautiously until it managed to achieve some impact in the following decade with the Integrated Evaluation of Schools programme. The implementation of another model is currently underway, the External Evaluation of Schools, where all state educational establishments have been, or will be, included in the same evaluation cycle (20062011). Bearing this experience in mind, this article briefly contextualises and critically reflects essentially on the self-evaluation component of this last model of institutional evaluation of Portuguese schools.

Keywords: Education policies, Institutional evaluation, Self-evaluation, Portugal, Schools. 


\section{INTRODUÇÃo}

Nas últimas três décadas, temos vindo a assistir, em diferentes contextos nacionais (e naturalmente também em Portugal) a mudanças mais ou menos profundas nas orientaçóes para a Educaçáo e nos pressupostos a partir dos quais se reestruturam ou redefinem as respectivas políticas públicas. Entre outros factores, essas políticas não são indiferentes às mutaçóes no papel do Estado (Afonso, 1999), à internacionalizaçáo crescente do capitalismo e ao papel das organizaçóes internacionais e supranacionais (Teodoro, 2008; Antunes, 2008). As políticas de avaliaçáo (dos alunos, dos profissionais da educação e das escolas) têm marcado o campo da educação, nomeadamente da educaçáo pública estatal, sendo justificadas por discursos muito díspares e contraditórios. Consoante os discursos, o enfoque pode conter a questão (ideológica e, num certo sentido, foucaultiana) do controlo e vigilância sobre os sujeitos, os métodos e os conteúdos da educaçáo, bem como referências, mais ou menos explícitas, à competitividade das economias, à eficácia e eficiência dos sistemas educativos, à compensação pela descentralização administrativa e pela autonomia, à melhoria da qualidade da educação, das performances e dos resultados escolares, ao direito à informação dos cidadãos contribuintes, ao apoio à decisão política, ao suporte a estratégias de comparativismo educacional baseadas em rankings de excelência, à livre escolha parental e ao mercado e quase-mercado de serviços educativos, e, entre muitas outras razóes que náo cabe aqui continuar a enumerar, à estruturação, ainda que parcial, de modelos de prestaçáo de contas e de responsabilização (accountability) ${ }^{1}$. No que diz respeito, mais especificamente, à avaliaçáo das escolas públicas portuguesas, as justificaçôes oficiais referem a importância de "fomentar nas escolas uma interpelação sistemática sobre a qualidade das suas práticas e dos seus resultados", a necessidade de "reforçar a capacidade das escolas para desenvolverem a sua autonomia", o objectivo de "concorrer para a regulação do funcionamento do sistema educativo" e a intençáo de "contribuir para um melhor conhecimento das escolas e do serviço público de educaçáo, fomentando a participação social na vida das escolas" ${ }^{2}$.

Assim, a avaliação institucional das escolas ou, simplesmente, a avaliação das escolas, inscrevendo-se num ímpeto avaliador que tem sido impulsionado, entre outros, pelos factores político-ideológicos, educacionais, económicos e

${ }^{1}$ Sobre a problemática da accountability em educaçăo, ver, por exemplo, Afonso (2009b, 2009c, 2010b). ${ }^{2}$ Ver a este propósito o site da Inspecçâo-Geral da Educação (http://www.ige.min-edu.pt). 
culturais atrás evocados, pode ser referenciada, consoante os casos, a modelos e experiências diversos que estão, eles próprios, em etapas de implementaçáo e consolidaçáo muito distintas.

No caso português, a avaliação das escolas começou por ter alguma visibilidade ao longo da década de noventa, nomeadamente com o Observatório da Qualidade da Escola e o Projecto Qualidade XXP, tendo evoluído discretamente até conseguir maior impacto no início da década seguinte com o Programa de Avaliaçáo Integrada das Escolas ${ }^{4}$. Actualmente, está em curso a concretização de um outro modelo, designado de Avaliação Externa das Escolas, em que todos os estabelecimentos de ensino estatais foram, ou serão ainda, incluídos num mesmo ciclo avaliativo (2006-2011) . Este último modelo é da responsabilidade da Inspecção-Geral da Educação ${ }^{6}$, mas conta com a colaboraçáo de especialistas convidados (em geral docentes e investigadores do campo das ciências da educaçáo), os quais integram as diversas equipas externas de avaliação.

Em termos de arquitectura global, este modelo ou programa de avaliaçáo externa prevê uma fase inicial para recolha e sistematização de informaçáo por parte das escolas ou agrupamentos de escolas ${ }^{7}$, que se traduz, entre outros aspectos, na produção de um relatório de auto-avaliação. Segue-se uma segunda fase

${ }^{3}$ O Projecto Qualidade XXI nasceu do projecto-piloto sobre Avaliação da Qualidade na Educação Escolar que foi uma iniciativa da Comissão Europeia para promover a auto-avaliaçáo e a avaliaçáo da qualidade. Ver, a este propósito, Maria do Carmo Clímaco (2005) onde esta especialista em avaliação institucional, para além da análise do projecto-piloto atrás indicado, refere também um dos primeiros projectos de auto-avaliação de escolas que foi lançado em Portugal, e de que é mentora - o Observatório da Qualidade da Escola - PEPT 2000.

${ }^{4}$ Para uma análise aprofundada deste programa, ver A. Ventura (2006).

5 Apesar de ter aspectos positivos, esta história (ainda recente) dos modelos de avaliação de escolas em Portugal constitui um percurso com descontinuidades e algumas consequências negativas porque "náo criou condiçôes para consolidar programas e projectos e favoreceu a sua relativizaçáo" (Azevedo, 2007, p.1).

${ }^{6}$ A Inspecção-Geral da Educaçáo (IGE) é um serviço central do Ministério da Educação português que, entre outras funçóes, "tem por missão assegurar o controlo, a auditoria e a fiscalização do funcionamento do sistema educativo no âmbito da educação pré-escolar, dos ensinos básico e secundário e da educação extra-escolar, [...]" (cf. Decreto-Lei no 213/2006, art ${ }^{\circ} 1^{\circ}$ ). ${ }^{7}$ Agrupamentos sáo conjuntos de escolas que trabalham sob a mesma direcçáo e gestáo, e que orientam a sua actividade lectiva e educacional por referência a um mesmo projecto educativo (idêntico ao projecto político-pedagógico que existe nas escolas brasileiras). Há, todavia, em alguns casos, escolas que não estáo integradas em agrupamentos. 
em que os vários documentos produzidos e os dados e informações sistematizados são disponibilizados e analisados pelas respectivas equipas externas de avaliaçâo, com o objectivo de prepararem adequadamente a visita que cada equipa fará às escolas ou agrupamentos que lhe forem atribuídos ${ }^{8}$. Numa terceira fase, durante a visita da equipa externa de avaliaçáo (constituída por dois elementos da Inspecção-Geral da Educação e um especialista convidado), realizam-se diferentes entrevistas em painel onde são ouvidos, durante dois ou três dias, membros e representantes de todos os sectores da comunidade educativa (membros de órgáos de direcção e gestão, professores, funcionários, estudantes, pais, representantes das autarquias e de outras instituições ou associaçóes locais...). Estas entrevistas, seguindo um guiáo genérico e idêntico para todas as equipas, procuram esclarecer e aprofundar aspectos incluídos nos documentos, dados estatísticos e relatórios parcelares elaborados inicialmente pelas escolas ou agrupamentos, constituindo-se, assim, como oportunidades de diálogo, justificação e argumentação entre a equipa externa de avaliação e os actores educativos. Trata-se claramente, do meu ponto de vista, de uma fase típica de prestação de contas interna à organizaçáo escolar (Afonso, 2009b, 2010a). Nesta mesma ocasião, e de acordo com um guiáo previamente definido, são recolhidas informaçóes e explicaçóes pertinentes relativas aos domínios dos resultados, prestação do serviço educativo, organização e gestão escolar, liderança e capacidade de auto-regulação, bem como dados mais específicos sobre sucesso académico, participação e desenvolvimento cívico, comportamento e disciplina, valorização e impacto das aprendizagens, articulação e sequencialidade dos currículos, acompanhamento da prática lectiva em sala de aula, diferenciação de apoios pedagógicos, valorização dos saberes e aprendizagens, concepção, planeamento e desenvolvimento das actividades educativas, gestão dos recursos humanos, materiais e financeiros, participaçáo dos pais e outros elementos da comunidade educativa, equidade e justiça, visão e estratégia de desenvolvimento futuro, motivação e empenho, abertura à inovação, parcerias, protocolos e projectos, auto-avaliaçáo, e, ainda, sustentabilidade do progresso educativo.

${ }^{8}$ Neste aspecto, num grande número de países, "os avaliadores recolhem e analisam sistematicamente documentação sobre a escola antes de a visitarem, como forma de melhor prepararem o seu trabalho. Essa documentação inclui relatórios administrativos, estatísticos ou financeiros, queixas apresentadas, resultados de testes ou exames internos ou externos, avaliaçóes precedentes, questionários efectuados junto dos pais ou do pessoal e documentos preparados e fornecidos pela escola (brochuras de apresentação, projecto educativo e curricular, projecto de comunicação, etc.). Quanto mais extensa e intensa é a avaliação, mais desenvolvido é este trabalho prévio" (Conselho Nacional de Educação, 2005, p. 20). 
Depois de serem efectuadas estas entrevistas em grupo, e concluída a respectiva visita à escola ou agrupamento de escolas, cada equipa externa de avaliação pondera as informaçóes e dados recolhidos, atribui uma classificaçáo a cada um dos domínios avaliados (que vai de insuficiente a muito bom), sinaliza o que considera serem os pontos fortes e fracos da organizaçáo escolar visitada, e elabora um relatório final que, depois de submetido a olhares críticos de outros pares (no que poderia constituir uma espécie de validação intersubjectiva), é enviado, algum tempo depois, aos respectivos agrupamentos ou escolas não agrupadas. Recebido o relatório, o agrupamento ou a escola que julgar pertinente fará o contraditório, ou seja, apresentará as razóes pelas quais possa não estar de acordo com as classificaçóes atribuídas, podendo, em decorrência disso, ser introduzidas correcçóes relativas a dados factuais ${ }^{9}$. Quer o relatório da equipa externa de avaliaçáo quer o contraditório (quando houver) são posteriormente publicados no site da Inspecção-Geral da Educaçâo (com acesso público sem restriçóes). Mais recentemente, visando atender a solicitaçóes dos directores de escolas, está em vias de ser "instituída uma instância de recurso" para reanalisar, quando necessário, as classificaçóes atribuídas no relatório final de avaliação externa.

\section{A AUTO-AVALIAÇÃO NO ÂMBITO DA AVALIAÇÃO INSTITUCIONAL}

No que diz respeito, mais especificamente, à componente de auto-avaliação das escolas, se era possível afirmar, há uma década atrás, que não havia em Portugal uma tradição significativa nesse domínio (Afonso, 2001), apesar de algumas iniciativas importantes já então realizadas ou em realização, hoje a realidade é outra, nomeadamente porque há orientaçóes legais para todo o sistema educativo em termos de auto-avaliaçãa ${ }^{10}$. As escolas dos ensinos básico e secundário já desenvolvem dispositivos, instrumentos e processos diversos, como consequência dessas orientaçóes

9 "No caso da avaliação das escolas, por exemplo, discute-se com frequência a adequaçăo dos indicadores em relação às dimensóes, mas problematiza-se muito pouco as próprias dimensóes, $\mathrm{e}$ menos ainda a hierarquia das metas e dos objectivos educativos. Um exemplo paradigmático do efeito de ofuscaçáo da face técnica sobre a face política da avaliação pode ser encontrado nos "contraditórios" produzidos pelas escolas a propósito das avaliaçōes externas realizadas pela IGE. Com frequência as escolas "queixam-se" de que não se "mediu" bem este ou aquele aspecto, mas raramente se "intrometem" na problematização do que se avalia e para que se avalia” (Sá, 2009, p. 3801).

${ }^{10}$ É de assinalar a existência da Lei no $31 / 2002$ que aprova o sistema de avaliaçăo da educaçáo e do ensino não superior e que se aplica "aos estabelecimentos de educaçáo pré-escolar e de ensino básico e secundário da rede pública, privada, cooperativa e solidária”. 
legais ou como consequência do actual programa de avaliação externa, do qual é responsável a Inspecção-Geral da Educação. Aliás, a legislação em vigor não apenas refere que a "avaliação estrutura-se com base na auto-avaliação, a realizar em cada escola ou agrupamento de escolas, e na avaliaçáo externa", mas também especifica que "a auto-avaliação tem um carácter obrigatório [e] desenvolve-se em permanência" (Lei no 31/2002, $\operatorname{art}^{\circ} 5^{\circ}$ e $\left.\operatorname{art}^{\circ} 6^{\circ}\right)^{11}$.

A auto-avaliação, todavia, tem estado a ser concretizada através de processos e modos muito heterogéneos, nomeadamente em termos de fundamentação e consistência teórico-metodológica. Neste sentido, alguns agrupamentos de escolas e escolas náo agrupadas, ou tentam operacionalizar modelos referenciados na literatura especializada, ou importam mimeticamente experiências realizadas noutros contextos, ou recriam e adaptam modelos, eixos estruturantes ou apenas linhas orientadoras, ou, simplesmente, assumem que estáo numa fase de exploração e desenvolvimento de percursos formativos autónomos tendo como objectivo o domínio de saberes e metodologias da auto-avaliação, metodologias essas supostamente mais congruentes com as respectivas culturas organizacionais ou com um determinado ethos escolar. Não deixa ainda assim de ter significado o facto de alguns agrupamentos de escolas ou escolas não agrupadas procurarem conhecer e operacionalizar modelos "prontos a usar (e a comprar)" (Simóes, 2007, p. 40). Nesse sentido, não é de todo irrealista falar de um emergente e ainda incipiente mercado (e/ou quase-mercado) direccionado para a avaliação institucional e, mais especificamente, para a auto-avaliação. Trata-se de uma oferta e procura impulsionadas, quer pelas necessidades decorrentes da

${ }^{11}$ Esta Lei refere ainda que a auto-avaliação “assenta nos termos de análise seguintes: a) Grau de concretizaçáo do projecto educativo e modo como se prepara e concretiza a educação, o ensino e as aprendizagens das crianças e alunos, tendo em conta as suas características específicas; b) Nível de execução de actividades proporcionadoras de climas e ambientes educativos capazes de gerarem as condiçóes afectivas e emocionais de vivência escolar propícia à interacção, à integração social, às aprendizagens e ao desenvolvimento integral da personalidade das crianças e alunos; c) Desempenho dos órgãos de administraçáo e gestáo das escolas ou agrupamentos de escolas, abrangendo o funcionamento das estruturas escolares de gestáo e de orientaçáo educativa, o funcionamento administrativo, a gestáo de recursos e a visáo inerente à acçáo educativa, enquanto projecto e plano de actuação; d) Sucesso escolar, avaliado através da capacidade de promoção da frequência escolar e dos resultados do desenvolvimento das aprendizagens escolares dos alunos, em particular dos resultados identificados através dos regimes em vigor de avaliaçâo das aprendizagens; e) Prática de uma cultura de colaboração entre os membros da comunidade educativa" (Lei no 31/2002, $\operatorname{art}^{\circ} 6^{\circ}$ ). 
legislaçáo actual, quer pelas dificuldades inerentes da ausência de uma prática consolidada de auto-avaliação, quer pela escassa formação dos actores educativos nestas e noutras áreas da avaliação ${ }^{12}$.

Se hoje já é possível verificar empiricamente que formas de auto-avaliação existem ou são praticadas, também já podemos conhecer melhor as motivaçóes (ou induçóes) que impulsionam os actores escolares, e as leituras e convicçóes que os mesmos desenvolvem a partir desta experiência ${ }^{13}$. Num momento em que estão em curso processos de transição para formas de governança (que coexistem com, ou tendem mesmo a substituir, as velhas formas de governação), a adopção de algumas medidas que visam a descentralização de responsabilidades e a subsequente avaliaçáo das acçóes e das decisôes locais e institucionais relativas à implementação das políticas educativas centralmente definidas, podem constituir, não apenas estratégias de governança, como (também) estratégias de legitimação não desprezíveis.

${ }^{12}$ Começam também a ser desenvolvidos projectos de pesquisa e/ou de formação que são apresentados visando aumentar a capacidade dos actores escolares para concretizarem a autoavaliação com maior fundamentação teórica e metodológica. Apenas a título de exemplo, ver o projecto PAR - Projecto de Avaliaçáo em Rede. Auto-Avaliação de Escola (http://www.esas. pt/avesas/docs/Projecto_PAR_.pdf), ou o Projecto ARQME - Auto-Avaliaçáo em Agrupamentos: Relação com Qualidade e Melhoria da Educação (http://paginas.fe.up.pt/-gei05010/ arqme/index.php). Sobre estes e outros projectos similares, ainda é cedo para perceber melhor as motivaçóes e implicaçóes subjacentes. De qualquer modo, como chama a atençāo um autor, "será importante a produção de conhecimento situado, não num sentido instrumental e pragmático, para dizer às escolas como fazer, mas num sentido compreensivo, levantando pontas de questionamento que 'aumentem a reflexividade crítica dos actores' [...] e reforcem a componente cognitiva dos processos de auto-avaliação [...]" (Simóes, 2007, p. 41). Curiosamente, há mais de uma década, também Perrenoud escreveu: "Há que se temer [...] um desenvolvimento anárquico de um 'mercado da avaliaçáo' em expansão, que levaria avaliadores mal formados ou irresponsáveis a causarem estragos" (Perrenoud, 1998, p. 200).

${ }^{13}$ Foi justamente a este propósito que, há alguns anos, escrevi: “[...] náo há em Portugal qualquer tradição de auto-avaliaçáo das escolas do ensino básico e secundário que possa servir de referência aos actores educativos que se mostrem interessados em constituí-la, quer como antídoto à avaliação externa, quer como forma de resistência, quer, ainda, como forma de avaliaçâo complementar ou compensatória" (Afonso, 2001, p. 24). Certamente que estas náo são as únicas nem talvez as verdadeiras motivaçôes que justificam, no contexto actual, a autoavaliaçáo das escolas. Neste sentido, o conhecimento mais sustentado dos processos em curso, nomeadamente em termos de pesquisa teórica e metodologicamente orientada, pode revelar-se muito pertinente para o conhecimento e compreensáo desta nova realidade da vida das escolas. 
Neste contexto, a desocultação, por parte dos actores educativos locais e institucionais, das funçôes latentes ou dos limites subjacentes a um modelo de autoavaliaçáo induzido ou impulsionado externamente (como acontece no modelo português em vigor), poderá vir a ter, pelo menos, duas consequências importantes: ou os actores educativos, com o passar do tempo, tenderão a naturalizar (ou mesmo a subverter) os procedimentos de auto-avaliaçâo, obrigando a reajustamentos periódicos para manter e reactualizar a sua eficácia real e simbólica, ou, entáo, as escolas tenderâo a reivindicar e assumir formas de auto-avaliação que as protejam de uma eventual instrumentalização da sua autonomia, e lhes permitam contrabalançar os efeitos (eventualmente negativos) das formas de avaliação externa. A perspectiva de colaboração benévola entre avaliação externa e autoavaliação, que assente na reciprocidade crítica e dialógica, não parece por agora totalmente garantida.

Aliás, a centralidade da avaliação externa (que o próprio nome do modelo evidencia) amplia necessariamente a secundarização da auto-avaliação, o que, mesmo assim, náo explica completamente o facto de esta última ser a componente de avaliaçáo institucional menos consolidada e valorizada. A este propósito, como mostram algumas análises e relatórios, "a auto-avaliação é um dos aspectos de desempenho das escolas que recolhe menos apreciaçóes positivas na avaliação externa" (Azevedo, 2007, p. 4) ${ }^{14}$.

Também como antídoto a esta eventualidade, continuo a pensar que a melhor forma de concretizar uma parte essencial da avaliaçáo institucional é apostar com determinação numa política pública que favoreça a prática de uma auto-avaliação motivadora, sustentada, formativa e promotora de empowerment, a partir da qual possa haver um diálogo solidário, mas profundamente analítico, crítico e consequente, com equipas interdisciplinares externas às escolas.

É também por isso que tenho reafirmado que uma ampla formação em avaliação (para professores e outros actores educativos com responsabilidades importantes nas escolas) é absolutamente decisiva. Sem essa competência, que se deve acrescentar a todas as outras que são constitutivas de uma concepção avançada em termos profissionais (nos domínios éticos, metodológicos, políticos, científicos, pedagógicos, organi-

${ }^{14}$ Como refere igualmente um relatório da IGE, "As apreciaçōes produzidas e as classificaçốes atribuídas no domínio 5 [capacidade de auto-regulação e melhoria da escola/agrupamento], em sede de avaliaçẫo externa, evidenciam a fragilidade e a falta de continuidade nas práticas de auto-avaliação de muitas escolas" (Portugal, 2009, p. 70). 
zacionais ${ }^{15}$...), o discurso oficial da necessidade de promover uma cultura de avaliação, já transformado num novo senso comum educacional, é mais um slogan ideológico.

$\mathrm{Na}$ ausência de uma confiança forte nos profissionais da educaçáo (sobretudo nos professores), e perante a emergência dos novos mecanismos de governança, será plausível esperar, em Portugal e noutros contextos, que os sistemas de avaliaçáo acabem sobretudo por justificar a expansão (e eventual tecno-burocratização) de estruturas especializadas para a sua gestâo e implementação, induzindo a criação de patamares de meta-avaliação mais adequados ao protagonismo e exercício do poder dos especialistas, eventualmente recrutados por organizaçóes específicas e com ampla autonomia em relaçáo ao Estado, mas, com grande probabilidade, radicalmente afastados dos interesses (e das vozes) dos actores educativos e das especificidades dos contextos locais e institucionais. Aliás, sem a participação crítica e empenhada dos interessados haverá maior probabilidade de separar a questão da responsabilização dos actores educativos da questão das possibilidades e limites da avaliabilidade desses mesmos actores, organizaçôes e contextos (Afonso, 2002). Neste caso, por exemplo, será mais fácil aceitar as consequências negativas de um modelo de avaliação enquanto subsistirem lacunas de formação e eventual alheamento em relação a políticas e agendas educacionais, nomeadamente em relaçâo a programas, metodologias e procedimentos que devem, com envolvimento dos sujeitos, estar direccionados para a descrição, compreensão e mudança das realidades educacionais.

No caso da experiência portuguesa relativa ao modelo de avaliação externa das escolas, os procedimentos metodológicos, éticos e organizativos têm sido sucessivamente discutidos e aperfeiçoados (essencialmente pela IGE e pelos especialistas envolvidos), mas, mesmo assim, vai sendo generalizada a convicção de que subsistem aspectos problemáticos a confrontar de forma mais efectiva, mesmo porque o modelo contém dimensóes de accountability que ainda precisam de melhor clarificação e especificação. A este propósito, por exemplo, se concebermos a accountability como um conjunto articulado de avaliaçáo, prestação de contas e responsabilização (Afonso, 2009b, 2010a), é evidente, no actual modelo de avaliaçáo externa das escolas, a centralidade do pilar da prestação de contas (onde

${ }^{15}$ A formação sociológica e organizacional, entre outras, deve ter também um espaço no que diz respeito à avaliaçáo educacional, neste caso, à avaliação institucional. Como escreve Licínio Lima, "O estudo das concepçóes organizacionais de escola mais influentes nas políticas e nas práticas de avaliação educacional permite não apenas articular analiticamente as modalidades e as tecnologias de avaliaçáo com as 'lógicas de acção' organizacional, mas também esclarecer que quadros de racionalidade, que valores, que objectivos e interesses sáo perseguidos pelas políticas educativas, também em função dos níveis de análise ensaiados pelo investigador, dos diferentes lugares, da diversidade dos actores e dos processos envolvidos" (Lima, 2006, p. 28). 
a produção de informaçóes, argumentaçōes e justificaçóes tem um papel estruturante), estando também presente o pilar da avaliaçáo, em dois momentos distintos: durante o processo de auto-avaliação interna e durante o processo de ponderação e elaboração do relatório de avaliaçáo externa. No entanto, observa-se uma insuficiente traduçáo ou assunção do pilar da responsabilização, apesar de estarem previstas, em outros normativos legais, algumas consequências concretas dependentes dos resultados desta avaliação externa. É o caso, entre outros, dos contratos de autonomia das escolas ou agrupamentos de escolas, os quais não podem ser celebrados à margem da avaliação externa ${ }^{16}$, ou, ainda, das quotas que serão estabelecidas para a atribuição das menções mais elevadas na avaliação dos professores ${ }^{17}$.

A compreensão sociológica de alguns dilemas e tensōes em termos de avaliação institucional, nomeadamente no que diz respeito à componente de auto-avaliação das escolas, pode ser ampliada se, por exemplo, tivermos em consideração a configuração complexa de uma instituição (e organização) como a escola pública portuguesa.

\section{A ESCOLA PÚBLICA PORTUGUESA COMO INSTITUIÇÃO E ORGANIZAÇÃO COMPLEXA}

A Escola, enquanto instituição educativa, é uma criaçẫo histórica com características e missóes peculiares, que resultam, entre outros factores, de longos e contraditórios processos sociais, políticos, culturais e pedagógicos (entre outros, Lima, 2005; Canário, 2008). As escolas concretas, por sua vez, reconstroem-se e reactualizam-se quotidianamente pela acção pedagógica e organizacional, quer pela forma

${ }^{16}$ De acordo com o Decreto-Lei no 75/2008, "Por contrato de autonomia entende-se o acordo celebrado entre a escola, o Ministério da Educaçáo, a câmara municipal e, eventualmente, outros parceiros da comunidade interessados, através do qual se definem objectivos e se fixam as condiçóes que viabilizam o desenvolvimento do projecto educativo apresentado pelos órgáos de administração e gestáo de uma escola ou de um agrupamento de escolas". Por outro lado, o mesmo normativo refere: "A extensáo da autonomia depende da dimensáo e da capacidade do agrupamento de escolas ou escola não agrupada e o seu exercício supóe a prestação de contas, designadamente através dos procedimentos de auto-avaliação e de avaliação externa" (art ${ }^{\circ} 57$, ponto 1 e arto 8 , ponto 2 ).

17 "Por despacho conjunto dos membros do Governo responsáveis pelas áreas da educação e da Administraçáo Pública são fixadas as percentagens máximas para a atribuição das classificaçóes de Muito bom e Excelente, por escola não agrupada ou agrupamento de escolas, as quais terão por referência os resultados obtidos na avaliaçáo externa da escola" (Decreto-Lei $n^{\circ} 270 / 2009$, art ${ }^{\circ} 46$, ponto 3). Para uma interessante análise sobre a avaliaçáo dos professores portugueses, e também suas relaçóes com o modelo actual de avaliaçáo externas das escolas, ver, por exemplo, Morgado e Sousa (2010). 
como incorporam, referenciam ou resistem a certas heranças simbólicas, representações sociais e "sedimentos culturais"18, quer pela forma como encaram, com maior ou menor capacidade de iniciativa e criatividade, os constrangimentos, dilemas e oportunidades, ou como assumem e concretizam novas missóes e objectivos.

No contexto português actual, esta acçáo quotidiana é marcada, entre muitos outros factores, pela crescente presença e diversidade de actores (internos e externos) e pela contraditória heterogeneidade de expectativas e exigências que expressam, bem como pela sobreposiçáo (e "transbordamento") de mandatos educativos ${ }^{19}$. Tudo isto em meio a uma previsível tendência para acentuaçáo dos défices de financiamento e outros constrangimentos similares, que se cruzam ou interagem com uma maior pressão para a redefiniçáo do papel do Estado e ressignificação do conceito de educaçáo pública, num contexto social e político em que se fazem sentir, cada vez mais, as consequências dos novos processos de governança e regulação.

Não é por acaso que florescem as parcerias e se diversificam os projectos e convénios, os quais constituem náo apenas uma forma de ampliação da comunidade educativa (em termos reais e simbólicos), mas, também, uma formalização de colaboraçóes e busca de soluçóes, mais ou menos especializadas, que a escola necessita e que náo consegue, por si mesma, suprir adequadamente ${ }^{20}$.

${ }^{18}$ A este propósito, Leonor Torres escreve: "[...] propusemos a ideia de sedimentos culturais para dar conta de um património cultural e simbólico historicamente depositado na memória colectiva da instituição e que resultou do labor antropológico de apropriação das várias possibilidades da estrutura, nos vários espaços-tempo educativos da escola. Compreendeu-se que, mesmo em quadros de elevado constrangimento estrutural, a organização escolar conseguia gerar novas camadas sedimentares e realimentar o seu património cultural comum" (Torres, 2008, p. 64). ${ }^{19}$ Como tem vindo a chamar a atençấo António Nóvoa (2007, p. 26-27), "A escola está esmagada, sufocada, por um excesso de missōes", sendo, por isso, necessário pensar o seu "retraimento".

${ }^{20} \mathrm{~A}$ proliferaçáo de projectos de educação formal e não formal no âmbito da escola pública, referenciáveis a distintos objectivos, dimensôes e tipologias, distancia-se, neste caso, da projectocracia que alguns autores têm vindo a questionar (ver, por todos, Caramelo, 2009). A situação portuguesa também parece diferente daquela que Andy Hargreaves descreve quando refere que há "sistemas dotados de pouca capacidade instalada [...] onde muitos dirigentes se vêem mais como gestores do que como líderes no âmbito do ensino e da aprendizagem e nos quais os recursos são escassos, ou se distribuem de forma demasiado dispersa entre diversas iniciativas - aquilo a que chamo a praga da projectite" (Hargreaves, 2003, p. 250). No caso português, pelo contrário, a disseminaçáo de projectos, muitos dos quais financiados externamente por diversas entidades, parece ser para muitas escolas uma oportunidade significativa para captar recursos materiais e educacionais suplementares e aumentar assim a capacidade de gestão. 
Em meio a estas variáveis, e mais importante do que tudo, está o facto de as escolas públicas portuguesas se sentirem, nos dias que correm, particularmente submetidas a fortes pressóes externas, quer da parte do Estado, quer da parte da sociedade em geral, com contornos que parecem traduzir-se na compatibilizaçáo provisória de duas dimensóes aparentemente paradoxais: por um lado, a tendência, essencialmente visível no ensino secundário (ensino médio), para uma crescente selectividade em termos de performances e padróes académicos desejáveis, sobretudo no que diz respeito aos percursos que pretendem levar mais directamente à continuidade dos estudos em determinados cursos universitários; por outro, o reconhecimento empírico da permanência de importantes desigualdades escolares, que tendem a ser retoricamente convocadas como justificaçâo para a existência (ou inevitabilidade) de uma maior oferta de percursos escolares e formativos alternativos, os quais, em muitos casos, são frequentados maioritariamente por filhos das classes trabalhadoras.

No primeiro caso, trata-se de introduzir lógicas mais competitivas (e supostamente mais meritocráticas) através da produção e constante melhoria de resultados mensuráveis - objectivo facilmente perceptível nos discursos e orientaçôes dominantes que traduzem uma clara obsessão avaliativa de cariz quantitativista e comparativista (Afonso, 2007). No segundo caso, e numa lógica supostamente mais igualitária, trata-se da gestáo, pretensamente mais eficaz e eficiente, das diversidades escolares (que não sendo sempre reconhecidas no seu sentido mais profundo, são, essencialmente, o outro lado das desigualdades sociais, raciais, de género, entre outras).

No contexto da escola pública portuguesa isto expressa bem a tensão (mais ou menos eficazmente dissimulada) entre, por um lado, a construção da ideia de excelência que alimenta certos percursos de escolarização destinados aos herdeiros e, por outro, a massificação (ou igualização por baixo) que é legitimada no princípio da igualdade formal de oportunidades, ou no pressuposto (democrático) do direito de todos(as) a um minimo cultural comum ${ }^{21}$.

As escolas públicas são, por isso, lugares de explicitação e confronto de exigências e expectativas divergentes e plurais, em permanente reactualização, nunca indiferentes às culturas e condiçóes sociais das famílias, e às trajectórias de professores e alunos, ainda que constituam tempos e espaços organizacionalmente estáveis, mas, nem por isso, impermeáveis à crescente incerteza, tensão, imprevisibilidade e risco.

${ }^{21}$ Esta última expressão está inserta no já célebre relatório "Propositions pour l'enseignement de l'avenir" elaborado pelo Collège de France e redigido por Pierre Bourdieu em 1985 (Collège de France, 1987). 
Se há, de facto, da parte dos professores, disponibilidades profissionais, relacionais e cognitivas diferentes, e investimentos emocionais não desvinculáveis de ciclos de vida profissional e de condiçóes de trabalho, há também, da parte dos alunos, constrangimentos sócio-familiares vários, expectativas e necessidades ambivalentes, ao mesmo tempo em que todos eles vão construindo percursos de vida e biografias com expectativas, possibilidades, realizaçóes, sucessos e insucessos de natureza diversa e idiossincrática. De igual modo, tal como ocorre com outros actores educativos, os directores (enquanto gestores) têm diferentes visóes educacionais e políticas, e distintas qualificaçōes, experiências, empenhos, motivaçóes e capacidades de potenciar ou mobilizar os graus de autonomia relativa (ainda) disponíveis. Além disso, o Estado central e os municípios sáo agentes e actores interessados na vida das escolas, porque as criam, apoiam, apetrecham ou financiam, e porque esperam (tal como a sociedade no seu todo, e a comunidade, em particular) que elas sejam espaços e tempos fundamentais para a prossecução de determinadas funções sociais e educacionais. As escolas públicas são, por isso, instituiçóes educativas de enorme complexidade.

Por estas e outras razóes, não é qualquer forma ou modalidade de avaliação institucional (e de auto-avaliaçáo) que pode dar conta, com a objectividade e justiça possíveis, da multidimensionalidade e complexidade das escolas públicas enquanto instituiçóes (e organizaçóes) educativas específicas.

\section{OUTROS ASPECTOS DA AVALIAÇÃO INSTITUCIONAL E DA AUTO-AVALIAÇÃO}

Como em qualquer outra modalidade de avaliação, também a avaliação de uma organizaçáo educativa (nomeadamente quando se trata de uma organização pública) ${ }^{22}$ deve guiar-se por valores e princípios fundamentais, entre os quais, a participação, o diálogo, a transparência, a justiça, e o rigor metodológico e ético, visando o conhecimento, o mais objectivo possível, das orientaçóes e meso-políticas

${ }^{22}$ No caso da escola pública portuguesa - lugar de escolarizaçáo (ainda) procurado por todos os grupos e classes sociais - o princípio do bem comum é desafiado quotidianamente pela tensão das diferenças e pelas desigualdades sociais, culturais e educacionais em confronto. Esta característica da escola pública portuguesa é bastante diferente, por exemplo, da escola pública brasileira. Nesta última, sobretudo nos níveis de escolaridade básica, a pertença de classe dos alunos é, supostamente, mais homogénea pelo facto de haver uma oferta significativa de ensino privado que concorre com o público e que, como consequência, absorve uma parte da procura, sobretudo, neste caso, dos filhos das classes médias. 
definidas, e a compreensão dos processos pedagógicos, científicos, administrativos, relacionais, ou quaisquer outros, que estejam, directa ou indirectamente, articulados com a educação.

Sendo a escola pública um espaço onde se actualizam relaçóes de poder, conflito e negociação, e um lugar onde se expressam interesses e perspectivas divergentes, e objectivos frequentemente não consensuais, não é fácil construir formas de autoavaliação autónomas que sejam estruturadas tendo como base processos de reflexividade, ainda que estes processos favoreçam o envolvimento crítico e criativo dos professores, educadores e outros actores educativos. Neste sentido,

"[...] não é pelo facto de poder ser controlada pelos actores da instituiçáo escolar que a auto-avaliação traz, por si, a eliminação de tensóes e conflitos, de perspectivas e interesses diferentes e mesmo contraditórios, designadamente entre professores ou entre estes e os pais. Apesar de ser uma forma potencialmente 'amigável' de avaliação, está longe de ser um processo isento de tensőes, o que constitui um factor adicional de dificuldade" (Conselho Nacional de Educação, 2005, p. 57).

Também a este propósito, escreve Philippe Perrenoud,

"Quando uma escola se engaja ela mesma numa auto-avaliação, com ou sem ajuda de especialistas, é possível esperar mais serenidade? De forma alguma, pois, desde o momento em que é ou pode ser tornada pública, uma auto-avaliaçâo é suscetível de servir ou desservir aos interesses da escola. [...] Mesmo que a auto-avaliação fique restrita a um uso exclusivamente interno, ela representa um desafio de bom tamanho, pois a escola está longe de ser uma 'grande família', já que é sempre permeada por tensões entre direçáo e corpo docente, entre diferentes tendências pedagógicas e ideológicas [...]. Numa escola, nenhum ator individual ou coletivo tem interesse na transparência total. Ao contrário, tornar evidentes certas falhas ou certos desempenhos do sistema ou de determinados profissionais sempre pode servir a algumas estratégias" (Perrenoud, 1998, p. 194).

Em síntese, a auto-avaliaçáo é um processo complexo e denso, havendo igualmente que perceber se a ilusão da (suposta) transparência de algo que é familiar aos sujeitos não poderá ser, também aqui, um obstáculo à compreensão da realidade educacional e organizacional.

Em qualquer caso, a auto-avaliaçáo das escolas deve ser um processo construído no respeito pela autonomia dos profissionais e das comunidades educativas, de- 
sejado e assumido por estes como uma necessidade de conhecimento profundo, sistemático e crítico da respectiva realidade social, organizacional e educacional, sem imposiçóes administrativas ou quaisquer consequências que possam ser interpretadas ou representadas como sançôes negativas, ou seja, deve ser um processo de natureza essencialmente formativa e conducente a uma melhoria global e sustentada de todos os dispositivos, estratégias e práticas que visem uma educação de qualidade, simultaneamente, em termos científicos, pedagógicos e democráticos.

Sendo a auto-avaliação uma dimensáo estruturante da avaliaçáo institucional, ela deve poder ser confrontada dialógica e criticamente com formas (complementares) de avaliação externa, apoiadas, neste caso, por equipas interdisciplinares com margens expressivas de autonomia relativa e com competências amplas e sólidas em termos éticos, metodológicos, científicos e pedagógicos. Estas equipas deverão, do mesmo modo, ser alheias ou indiferentes a objectivos ou intençôes que visem ou estimulem a comparaçáo entre escolas, estando, antes, exclusivamente preocupadas com a compreensão dos processos e o conhecimento das especificidades, numa atitude essencialmente direccionada para ajudar a desenvolver, ao máximo, as possibilidades e potencialidades educativas de uma determinada escola (ou agrupamento de escolas).

Propóe-se, portanto, que o trabalho das equipas externas de avaliaçáo se consubstancie no diálogo crítico com as escolas, dando continuidade, nos momentos posteriores à primeira avaliaçáo, ao acompanhamento de processos de colaboraçáo que se possam traduzir na definição partilhada e consequente de planos e acçóes de melhoria, nas mais diversas dimensóes da vida dessa organização educativa e com implicação dos sujeitos.

A avaliação institucional, enquanto forma específica de avaliaçáo do trabalho das escolas no seu todo (nas dimensóes de provimento, financiamento, organizaçáo, gestão, recursos materiais e humanos, projecto educativo, oportunidades de melhoria, constrangimentos, motivaçóes, práticas docentes e discentes, envolvimento de pais e outros parceiros da comunidade, comportamentos, programaçóes, objectivos e resultados académicos, cívicos e educativos...), pode ser um instrumento importante de democratização, de conhecimento e de desenvolvimento emancipatório. Mas a avaliação institucional também contém, dependendo das circunstâncias e conjunturas, outros perigos e problemas. Se a avaliação institucional for motivada por razóes mais instrumentais, managerialistas, economicistas ou regulatórias, ela pode ser também um instrumento de controlo hierárquico e de vigilância burocrática, reduzindo a autonomia e tornando-se, eventualmente, obsessiva em relação a 
resultados mensuráveis e quantificáveis, à margem dos processos humanos, relacionais e educacionais que tecem efectivamente a complexidade do quotidiano de uma escola, como a escola pública.

Aliás, a presença do Estado-avaliador ao nível do ensino não-superior expressase também pela promoção de um ethos competitivo (ao qual pode servir, em certas circunstâncias, a avaliaçáo externa das escolas), não sendo, por vezes, de estranhar o predomínio de uma racionalidade instrumental que tende a sobrevalorizar indicadores e resultados quantificáveis sem levar em consideraçáo os contextos e os processos educativos. Em muitas ocasiôes, a autonomia das escolas, mais retórica do que real, acaba assim por ser um pretexto para a avaliação e para a responsabilização dos sujeitos - o que é, aliás, absolutamente essencial para promover uma nova representação sobre o papel do Estado, agora cada vez mais distante das funçôes de bem-estar social e das obrigaçóes de principal provedor e fornecedor de bens e serviços educativos públicos.

Como acção humana complexa e ambivalente, a auto-avaliação é, em qualquer circunstância, tal como nos lembra Albert Hirschman, uma dimensão fundamental e distintiva da nossa condição, uma vez que uma "característica fundamental dos seres humanos é que eles são seres que se auto-avaliam, talvez os únicos entre os organismos vivos" (Hirschman, 1992, p. 158). Se outras razóes náo houvesse, essa não deixaria de ser uma boa motivação para retomar e aprofundar a problemática que foi objecto deste texto.

\section{REFERÊNCIAS BIBLIOGRÁFICAS}

AFONSO, A. J. Estado, mercado, comunidade e avaliação: esboço para uma rearticulação crítica. Educação \& Sociedade, Campinas, v.20, n. 69, p. 139-164, 1999.

As escolas em avaliação: avaliabilidade e responsabilização. Revista do Fórum Português de Administração Educacional, Lisboa, n. 1, p. 22-26, 2001.

. Políticas educativas e avaliação das escolas: por uma prática avaliativa menos regulatória. In: COSTA, J.; NETO-MENDES, A.; VENTURA, A. (Orgs.) Avaliação de Organizações Educativas. Aveiro: Universidade de Aveiro, 2002. p.31-37.
AFONSO, A. J. Estado, políticas educacionais e obsessão avaliativa. Contrapontos, Itajaí, v.7, n. 1, p. 11-22, 2007.

. Gestão, autonomia e accountability na escola pública portuguesa. "Breve diacronia". Revista Brasileira de Política e Administração da Educação, v. 26, n. 1, p.13-30, 2010a.

. Um olhar sociológico em torno da accountability em educação. In: ESTEBAN, $M$. T.; AFONSO, A. J. Olhares e Interfaces. Reflexões críticas sobre a avaliação. São Paulo: Cortez, 2010b. p.147-170.

Avaliação Educacional: regulação e emancipação. 4.ed. São Paulo: Cortez, 2009a. 
AFONSO, A. J. Políticas avaliativas e accountability em educação - subsídios para um debate iberoamericano. Sísifo - Revista de Ciências da Educação, Lisboa, n. 9, p. 57-70, 2009b. Disponivel em: <http://sisifo.fpce.pt/ pdfs/Revista\%209\%20AAFONSO.pdf>.

Nem tudo o que conta é mensurável ou comparável: crítica à accountability baseada em testes estandardizados e rankings escolares. Revista Lusófona de Educação, Lisboa, v. 13, n.1, p. 1329, 2009c.

ANTUNES, F. A Nova Ordem Educacional. Coimbra: Almedina, 2008.

AZEVEDO, J. M. Avaliação externa das escolas em Portugal. In: CONFERÊNCIA: AS ESCOLAS FACE A NOVOS DESAFIOS. Lisboa, 2007. Anais... Lisboa: Presidência Portuguesa da União Europeia. Disponível em: <http:// www.ige.min-edu.pt/upload\%5Cdocs/ AvaliacaoExternaEscolasportugal.pdf>.

CANÁRIO, R. A Escola: das 'promessas' às 'incertezas'. Educação Unisinos, Porto Alegre, v. 12, n. 2, p. 73-81, 2008.

CARAMELO, J. Educação e desenvolvimento comunitário num processo de transição autogestionário. 2009. Tese (Doutorado em Ciências da Educação). Faculdade de Psicologia e de Ciências da Educação, Universidade do Porto, Porto.

CLÍMACO, M. C. Avaliação de sistemas em educação. Lisboa: Universidade Aberta, 2005.

COLLĖGE DE FRANCE/BOURDIEU, P. Propostas para o ensino do futuro. Cadernos de Ciências Sociais, n. 5, p. 101-120, 1987.

CONSELHO NACIONAL DE EDUCAÇÃO. Estudo sobre 'Avaliação das escolas: fundamentar modelos e operacionalizar processos'. Lisboa: CNE, 2005.

HARGREAVES, A. O Ensino na sociedade do conhecimento. Porto: Porto, 2003.

HIRSCHMAN, A. O. Rival views of market society and other recent essays. Cambridge, Massachusetts: Harvard University, 1992.
LIMA, L. C. Concepções de escola: para uma hermenêutica organizacional. In:

(Org.). Compreender a escola: perspectivas de análise organizacional. Porto: Asa, 2006, p. 15-69.

Escolarizando para uma educação crítica: a reinvenção das escolas como organizações democráticas. In: TEODORO, A.; TORRES, C. A. Educação crítica e utopia: perspectivas para o século XXI. Porto: Afrontamento, 2005, p. 19-31.

MORGADO, J.C.; SOUSA, F. Teacher evaluation, curricular autonomy and professional development: trends and tensions in the Portuguese educational policy. Journal of Education Policy, v. 25, n. 3, p. 369-384, 2010.

NÓVOA, A. Conferência de apresentação. In: CONSELHO NACIONAL DE EDUCAÇÃO. Audições públicas no debate nacional sobre educação. Lisboa: CNE, 2007, p. 19-34.

PERRENOUD, P. A Avaliação dos estabelecimentos escolares: um novo avatar da ilusão cientificista? In: BITAR, $H$. et al. (Org.). Sistemas de avaliação educacional. São Paulo: FDE, 1998, p. 193-204.

PORTUGAL. Decreto-Lei n. 75 de 2008. Aprova - regime de autonomia, administração e gestão dos estabelecimentos públicos da educação pré-escolar e dos ensinos básico e secundário. Diário da República, I série, n. 79, de 22 de abr. 2008.

Decreto-Lei n. 270 de 2009. Altera

- Estatuto da Carreira dos Educadores de Infância e dos Professores dos Ensinos Básico e Secundário. Diário da República, I série, n. 190, de 30 de set. 2009.

Lei n. 31 de 2002. Aprova o sistema de avaliação da educação e do ensino não superior. Diário da República, I série- $\mathrm{A}, \mathrm{n}$. 294, de 20 de dez. 2002.

PORTUGAL . Ministério da Educação. Inspecção Geral da Educação. Avaliação externa das escolas: relatório 2008-2009. Lisboa: IGE, 2009. Disponível em: <http://www.ige.min-edu. 
pt/upload/Relatorios/AEE_2009_Final.pdf >. Acesso em: 20 jun. 2010.

SÁ, V. Indicadores de desempenho, qualidade(s) e melhoria. In: CONGRESSO GALEGO-PORTUGUÊS DE PSICOPEDAGOGIA, 10., 2009, Braga. Actas... Braga: Universidade do Minho, 2009. p. 3795-3805.

SIMÕES, G. M. J. A Auto-avaliação das escolas e a regulação da acção pública em educação. Sísifo - Revista de Ciências da Educação, Lisboa, n. 4, p. 39-48, 2007. Disponivel em: <http:// sisifo.fpce.ul.pt/pdfs/04-04-GSim.pdf>.
TEODORO, A. (Org.). Tempos e andamentos nas políticas deeducação:estudosiberoamericanos. Brasília: Liber Livro, 2008.

TORRES, L. A Escola como entreposto cultural: o cultural e o simbólico no desenvolvimento democrático da escola. Revista Portuguesa de Educação, Braga, v. 21, n. 1, p. 59-81, 2008.

VENTURA, A. Avaliação $e$ inspeç̧ão das escolas: estudo de impacte do Programa de Avaliação Integrada. 2006. Tese (Doutorado). Universidade de Aveiro, Aveiro. 